\title{
POR UMA APRENDIZAGEM PELO ENCONTRO. EXPERIÊNCIAS APRENDENTES NA FORMAÇÃO DOCENTE ON-LINE
}

\author{
FOR LEARNING BY MEETING. LEARNING EXPERIENCES \\ IN ONLINE TEACHER EDUCATION
}

\author{
Jaqueline Magalhães Brum ${ }^{1}$ \\ Nilcéa Elias Rodrigues Moreira²
}

\begin{abstract}
Resumo: Este ensaio trata dos efeitos que emergem dos encontros experienciados nos percursos formativos de professora(e)s na modalidade a distância, na dimensão da relação entre afetos/afecções e aprendizagens. A aposta é de que, nos ambientes de formação docente online, a aprendizagem se dá pelo encontro, pelo afeto, e não apenas pela prescrição, pelo engessamento e pelo template. Busca problematizar as experiências aprendentes, criativas e inventivas que ocorrem em ambientes de formação a distância de professores promovidas em unidades de ensino da rede municipal de Vitória/ES, utilizando a plataforma Moodle, (denominada VixEduca). Utiliza alguns conceitos criados e/ou deslocados por Deleuze e Deleuze e Guattari, os quais ajudaram a pensar a formação docente a distância como espaço de criação e de aprendizagens agenciadas pelo afeto. Visa articular a perspectiva das redes de conversações ampliadas para as redes de conectividades virtuais como produtoras de encontros, conversas, afetos/afecções de alegria e conhecimento. Conclui que a força da formação docente a distância pode ser espaço potente de criação, encontros e aprendizagens inventivas.
\end{abstract}

Abstract: This essay deals with the effects that emerge from the encounters experienced in the training courses of teachers in the distance modality, in the dimension of the relationship between affects/affections and learning. The bet is that, in online teacher education environments, learning takes place through encounter, through affection, and not only through prescription, plaster and template. It seeks to problematize the learning, creative and inventive experiences that take place in distance training environments for teachers promoted in teaching units in the municipal network of Vitória / ES, using the Moodle platform (called VixEduca). It uses some concepts created and / or displaced by Deleuze and Deleuze and Guattari, who helped to think of teacher education at a distance as a space for creation and learning that are facilitated by affection. It aims to articulate the perspective of networks of extended conversations to networks of virtual connectivity as producers of meetings, conversations, affects /affections of joy and knowledge. It concludes that the strength of distance teacher education can be a powerful space for creation, meetings and inventive learning.

\section{Introdução}

Nesta escrita, reconhecemos que a EAD, como corpo educativo, é, também, um território de demarcações e de intensos processos de subjetivações se pensarmos apenas nas macropolíticas instituídas. Mas, em composição com a perspectiva Deleuziana e Espinosiana sabemos que outros possíveis se apresentam. Portanto, esta escrita trata dos efeitos que emergem dos encontros experienciados nos percursos formativos de professore(a)s, na modalidade a distância, na dimensão da relação entre afetos/afecções e aprendizagens.

\footnotetext{
${ }^{1}$ Universidade Federal do Espírito Santo.

${ }^{2}$ Universidade Federal do Espírito Santo. Secretaria de Educação de Vitória.
} 
Reconhecemos que os recursos tecnológicos permitem a produção de realidades virtuais que possibilitam o encontro, ainda que, geograficamente, os corpos estejam distantes. Estes encontros também enunciam os afetos da formação docente como linhas de forças que se conectam por meio da produção coletiva.

A aposta é de que, nos ambientes de formação docente on-line, a aprendizagem se dá pelo encontro, pelo afeto, e não apenas pela prescrição, pelo engessamento e pelo template. É pelo afeto que as intensidades de forças se movem e se constituem. Compreendemos que o automatismo, o cumprimento de tarefas, o modelo a ser seguido coexistem com uma discursividade e com uma inventividade que apontam para outros possíveis à formação docente em serviço nessa produção coletiva que reverberam em aprendizagens. Portanto, esse texto problematiza as experiências aprendentes, criativas e inventivas que ocorrem em ambientes de formação a distância de professores promovidas em unidades de ensino da rede municipal de Vitória/ES, utilizando a plataforma Moodle, (denominada VixEduca).

\section{Pensando alto...}

\subsection{Compondo afecções de afeto}

Vamos nos apropriar de alguns conceitos criados e/ou deslocados por Deleuze e Deleuze e Guattari, os quais ajudaram a pensar a formação docente a distância como espaço de criação e aprendizagens agenciadas pelo afeto. Assim iniciamos nossa discussão teórica indagando: $\mathrm{O}$ que é um corpo? O que pode um corpo?

Ainda não sabemos do que o corpo é capaz, das misturas e da potência de agir que um corpo pode provocar em outro. No entanto, sabemos que o que é vital em nós segundo Deleuze e Guattari (1997) são os "perceptos" e os "afectos", sendo os perceptos as sensações e os afectos os devires, forças que transbordam e que passam pelos perceptos positivamente ou negativamente. Assim coexistem em nós três espécies de ideias: afecções, noções e essências.

As ideias-afecções são capazes de promover bons encontros (paixões alegres - que aumentam a potência de agir) e maus encontros (paixões tristes - que diminuem ou inibem a potência de agir). Mas ainda estamos na condição do encontro e de como esse encontro pode nos afetar, mas não conhecemos seus efeitos ou causas. Portanto, são consideradas ideias inadequadas porque ainda nos encontramos nas paixões e separados da potência de agir. Para Deleuze (1978, p. 52)

"Ora, um corpo deve ser definido pelo conjunto das relações que o compõem, ou, o que vem a ser exatamente o mesmo, pelo seu poder de ser afetado. Enquanto vocês não souberem qual é o poder de ser afetado de um corpo, enquanto o apreendem ao acaso dos encontros, vocês não terão uma vida sábia, vocês não terão a sabedoria".

A partir do momento que somos capazes de compreender as causas, entramos na ideia-noção. A partir desse momento passamos a perceber a conveniência ou a inconveniência das relações estabelecidas entre corpos e nesse estudo corpos educacionais. As paixões tristes não compõem com o nosso corpo, mas as paixões alegres compõem uma relação comum entre os corpos. Os afetos de alegria nos movem na criação de noções comuns ao corpo que afeta e ao corpo que é afetado. A partir da ideia-noção atingimos nossa potência de agir e passamos a ter ideias adequadas. Portanto, “[...] É necessário fazer os encontros que nos convém” (DELEUZE, 1978, p. 63).

Já a ideia-essência seria o maior conhecimento que um corpo pode atingir e é composto por intensidades, ou seja, somos afetados pelo afeto e promovemos o afeto nos outros corpos com o qual nos relacionamos. Nessa condição, todo afeto é biopolítico, movendo forças ativas 
para que a potência se firme em graus de alegria os mais elevados possíveis, promovendo encontros a favor da alegria, compondo o mundo como em uma sinfonia... Essa conveniência pressupõe encontros de corpos humanos e não humanos produzindo noções comuns por meio dos afetos/afecções causados nos bons encontros.

Trazemos essas três noções para que possamos entender como a aproximação da Secretaria Municipal de Educação (SEME) e as unidades de ensino participantes desse projeto se deu de maneira afirmativa, como uma força ativa. Para Rolnik (2018) existem dois tipos de forças micropolíticas: reativas e ativas. As forças reativas em nada modificam o "status quo" uma vez que permanecem em repouso, ao passo que as forças ativas movimentam os corpos fazendo-os vibrar e sofrerem variações de intensidades.

É nesse contexto que a Plataforma Moodle se articula como potente espaço virtual na formação docente, conectando-se à política de usos de plataformas livres desenvolvida pela Secretaria de Educação de Vitória-ES. É esse e outros espaços online que compuseram a nossa pesquisa, na qual, por meio de rede de conversações (on-line), buscamos perscrutar o que emerge em afetos/afecções que ampliam a força de agir na formação docente.

Estes encontros com corpos orgânicos e não orgânicos, com os materiais, com as ideias e conhecimentos, nos movem a pensar a importância da sensibilidade dos corpos, pois, contradizendo a noção clássica de separação mente e corpo, Deleuze (2018) aposta na aprendizagem que se dá na relação, na tensão entre o pensamento e o corpo: entre o corpo do aprendiz e o corpo daquilo que está para ser aprendido. Nesse sentido essa escrita, reconhece que a EAD, como corpo educativo, é, também, um território de demarcações e de intensos processos de subjetivações. Em composição com a perspectiva Deleuziana e Espinosiana busca evidenciar a potência dos encontros experienciados na formação docente promovidas em unidades de ensino da rede municipal de Vitória/ES, utilizando a plataforma Moodle, (denominada VixEduca).

\section{Deslocamentos na formação}

Buscando os possíveis em meio à prescrição e controle, a proposta do projeto VixEduca foi utilizar-se desse intermeio (plataforma virtual) que como nos diz Kastrup (apud Dias, 2011, p. 30), "[...] comparece perturbando, e não transmitindo informações. Perturbar-se significa afetar, colocar problemas". É no acoplamento, no agenciamento maquínico do instrumento com o artista que conseguimos propor um deslocamento na formação, produzindo diferentes produtos e experiências.

Nesse sentido, Dias (2012, p. 23), tratando a formação inventiva como "possibilidade de deslocamento", assume a formação docente como espaço de aprendizagens para além da aquisição de habilidades e competências. Aposta em uma formação docente que engendre as aprendizagens, à procura de "[...] ressonâncias na composição entre educação, filosofia da diferença, políticas de cognição e arte" (p. 26).

Além disso, a autora alerta para a impossibilidade de tratar da formação docente sem que esta esteja atrelada aos problemas da aprendizagem, da cognição e da construção do conhecimento. A partir disso, propõe deslocamentos que forjem modos outros de conceber a docência em seus percursos formativos, "[...] buscando encontrar o que faz diferença, seus abalos, suas surpresas, suas rupturas, tensionando o pensamento hegemônico que padroniza a formação docente" (DIAS, 2011, p. 25).

Ao problematizar o conceito de cognição e seu amplo campo de abordagens teóricas, Dias (2012, p. 26) questiona o cognitivismo computacional (teoria da informação), que pressupõe a cognição como processamento de informação, no qual "[...] o sistema cognitivo recebe inputs, realiza seu procedimento por regras lógicas e os transforma em outputs". Ainda segundo a autora, essa perspectiva, no âmbito educacional, enuncia a noção de competência, transferindo 
a formação docente para outra noção, a de empreendedorismo educacional, em conexão com as forças capitalísticas. Em consonância com sua visão, consideramos que:

o problema de conhecer envolve uma posição em relação ao mundo e a si mesmo, uma atitude, um ethos. Pensando desta maneira, identificar a cognição ao modelo do processamento da informação, como faz o cognitivismo computacional, ou aproximá-la de um processo de invenção de si e do mundo não constitui apenas uma divergência teórica, mas também uma distinção ética, estética e política (DIAS, 2012, p. 29).

Assim, as problematizações apresentadas nos tópicos a seguir a partir dos enunciados produzidos pelos docentes de diferentes unidades de ensino da rede municipal de Vitória ES, dialogam com o conceito de formação inventiva proposto por Dias $(2011,2012)$, sobretudo, por considerarem o princípio ético-estético-político em que o "fazer com" se afirma pela experiência da formação docente compartilhada nos/dos/com os cotidianos das Escolas e Centros Municipais de Educação Infantil.

\section{O pensado e o vivido}

No ano de 2005, a Prefeitura de Vitória, por meio da Secretaria Municipal de Educação (SEME), firmou parceria com a União Europeia com o Programa URB-AL. Tratava-se, dentre outras ações, de um Projeto de Inclusão Digital para professores e demais profissionais ligados à formação na área de tecnologia da Informação e da Comunicação, em especial a informática. Em síntese, o objetivo da parceria era de possibilitar a formação continuada dos profissionais que atuavam como instrutores de Telecentros, mediadores de cursos de informática básica para comunidade, isto é, pessoas que atuavam na formação com as tecnologias, mas não possuíam uma formação pedagógica para a função.

A meta era ofertar cursos de aperfeiçoamento na área pedagógica. Nessa época como demanda da parceira, a Gerência de Tecnologias Educacionais fez um mapeamento de todas as instituições da cidade que ofereciam formação na área de informática para posteriormente ofertar possibilidades de formação, para este público (a última etapa prevista para execução do referido projeto seria a oferta do curso de formação pedagógica online para os profissionais que atuavam na formação junto à comunidade e/ou escolas). A aposta residiu na oferta de um curso utilizando o ambiente Moodle adaptado às necessidades emergentes. Essa seria a primeira versão do que hoje é conhecido como Plataforma VixEduca. Para cumprimento da demanda de parceria com o Projeto Urbano-América Latina (URB-AL) foi disponibilizado o curso Letramento Digital via ambiente "Educa" (como era denominado o VixEduca na época).

O curso foi oferecido em 2006 e 2007. Ao findar a parceria o ambiente permaneceu em desuso até que em 2009, quando foi incluída sua utilização nas ações do Programa Nacional de Tecnologia Educacional (PROINFO Integrado), parceria com o MEC. A Secretaria de Educação de Vitória-ES, por meio da Gerência de Tecnologias Educacionais, decide em reunião coletiva retomar o projeto do ambiente "Educa" para disponibilizar conteúdo e interação relativos ao curso de Ensinando e Aprendendo com as TIC. A partir desse período foram oferecidas duas turmas por semestre com essa temática de estudo e utilizando o novo nome Vix-Educa. Vale ressaltar que antes da implantação desse ambiente virtual as formações eram realizadas em sua maioria na modalidade presencial ou quando se firmava parceria com outras instituições que eventualmente disponibilizassem um ambiente de formação On-line para que o curso também pudesse ser feito de modo híbrido.

De modo sintético o fluxo para organização consistia em: 
a. A secretaria planeja, a partir de demandas apresentadas pelas unidades de ensino e também do próprio órgão gestor, formações continuadas utilizando a plataforma VixEduca como espaço de interação e hospedagem de conteúdos; Estas formações são ofertadas considerando os diferentes segmentos de profissionais atuantes na rede.

b. A Secretaria disponibiliza o espaço virtual na plataforma Moodle e a unidade escolhe a temática e apresenta o projeto para a Secretaria. A escolha de conteúdo, disparadores para os debates, vídeos, filmes e ferramentas de interação, são definidos pela unidade escolar.

Em 2017, 16 Centros Municipais de Educação Infantil (Cmei) e três escolas municipais de Ensino Fundamental (Emef) apostaram nesta experiência, que, em 2018, ampliou-se: foram 17 ofertas por Cmei e sete pelas Emef. Em 2019, 20 CMEI apostaram nesta experiência de formação e 11 EMEF. Já em 2020, 30 Centros Municipais de Educação Infantil estão utilizando o ambiente da plataforma para oferta e interação referentes aos cursos produzidos pela própria unidade de ensino, e 6 EMEF. Cerca de 6.000 usuários estão inscritos no AVA (VixEduca), em cursos ofertados pela Seme, pelas unidades escolares e também em parcerias com entidades e universidades.

As experiências aprendentes tecidas nos encontros com o conhecimento sobre o design do curso, com a apropriação da linguagem tecnológica, com a autonomia para produzir e buscar conteúdos em composição com as demandas formativas das unidades escolares manifesta-se em enunciados discursivos em que o(a)s professore(a)s, e outros(as) profissionais da educação em formação, expressam alegria e afetos potentes. Interessam nessa escrita esses modos outros de encontros que vão da composição do curso às conversações no ambiente VixEduca e nos momentos presenciais no fim dos turnos nas unidades escolares ${ }^{3}$. Ou seja, procuramos a cartografia como inspiração metodológica, apostando em redes de conversações cujos registros foram produzidos no desenrolar das conversas, engendrando-os com a problemática da investigação.

Trataremos, portanto, de encontros, de bons encontros, por compreendermos que a potência que resulta das experiências vividas são movimentos construídos nos percursos formativos, indo e voltando, em linhas incertas, moduláveis, que delineiam a experiência como acontecimento. A produção de dados para a composição desta escrita se deu em meio às redes de conversas tecidas nos fóruns e também via ferramentas on-line.

É nesse intermeio de tessitura das falas que compomos as redes de conversações, como modo de enunciar discursos que nos ajudarão a seguir as tramas desse complexo percurso que é a formação docente. Para tal, trazemos algumas falas:

Uma experiência gratificante em relação aos cursos promovidos pela VixEduca. Além dos temas serem bastante conectados com a realidade que vivenciamos em nossas unidades de ensino aí da nós possibilita o renovo profissional oportunizando o crescimento e aprimoramento profissional. [...]Um dos cursos muito relevante do qual participei e rende muitos frutos na nossa unidade de ensino foi em relação a Relações Étnico Raciais levando a uma reflexão mais atenta as questões étnicas e o modos e abordagem em nossas práticas pedagógicas (Professora 4, Formulário Google).

Com o início da pandemia, rapidamente alguns profissionais da Escola foram fazendo capacitações e montando pequenos cursos virtuais para os profissionais

\footnotetext{
${ }^{3}$ A respeito dessa dinâmica, destacamos que os cursos oferecidos pelas UE podem ter até $20 \%$ da carga horária a distância, sendo que os encontros presenciais ocorreram conforme apresentado nos projetos por elas enviados. Porém, neste ano de 2020, devido à pandemia causada pelo coronavírus, as experiências formativas foram em sua totalidade na modalidade a distância.
} 
de nossa Unidade de Ensino. Assim, fomos aprendendo a usar as ferramentas da Plataforma e aos poucos já estávamos montando atividades e dando nossas aulas virtuais. Para mim, foi muito positiva a implementação da Plataforma que não será somente para esse momento. Ganho real para continuar em nossas aulas após a pandemia (Professora 8, Formulário Google).

A opção de interagir, no decorrer da formação, entre os participantes..., não só por meio dos fóruns; Se torna espaço para desenvolvimento, não só profissional (Professora 1, Fórum Plataforma VixEduca).

Posso considerar excelente a comunicação entre tutoria e cursistas e dizer que interagir nesse espaço foi sempre uma ação positiva (Professora 13, Fórum Plataforma VixEduca).

É um processo permanente e contínuo de aprendizagem e reflexão sobre a prática pedagógica para a promoção de uma educação inclusiva, democrática, com qualidade social para professores e estudantes, considerando as diversas dimensões constitutivas do ser humano: éticas, estéticas, políticas, afetivas. É fundamental para acompanhar, orientar e avaliar por meio do assessoramento pedagógico os processos educativos nas Unidades Ensino, assumindo uma perspectiva dialógica na reflexão e na proposição de ações com vistas a potencializar os processos de ensino e aprendizagem (Professora 16, Formulário Google).

A plataforma VixEduca é uma ferramenta potente de formação, nos possibilita proporcionar formação para os nossos professores, mesmo nesse momento adverso que estamos atravessando. É um espaço interativo e dinâmico. Tive oportunidade de usar a plataforma como aluna, e esse ano como tutora. As duas experiências foram maravilhosas (Professora 17, Formulário Google).

A Plataforma VixEduca tem sido uma ferramenta que tem oportunizado muito aprendizado, esse espaço online foi uma inovação tecnológica para nós professores. Trabalhamos com a VixEduca desde o ano de 2017, naquele período ainda não havia muita adesão, mas hoje praticamente quase todas as unidades já aderiram. Ela é importantíssima, além de possibilitar que os cursistas realizem suas tarefas em qualquer e com qualquer aparelho (Professora 20, Formulário Google).

Acho interessante é uma forma prática da escola abrir diálogos e opinar sobre assuntos diversos, um local onde se pode aprofundar ideias referentes ao campo da educação (Professora 22, Formulário Google).

Nos ambientes virtuais de formação docente, diferentes modos de afetar e ser afetado coexistem em formas de encontros, ocorram eles por meio das ideias tecidas nos fóruns, e-mail, mensagens compartilhadas durante os trabalhos em grupo, nas interações que perpassam os espaços de notícias ou no "cafezinho".

Notamos, nos enunciados discursivos descritos acima, que a experiências de usos da plataforma VixEduca reverberam em afetos produzidos pelo conteúdo agenciado na formação sobre as relações étnico-raciais; pelas interações produzidas no espaço da plataforma; pela potência das aprendizagens nas dimensões éticas, estéticas e políticas.

\footnotetext{
${ }^{4}$ Espaço do AVA geralmente destinado à interação livre dos cursistas.
} 
Nesse contexto, é premente conhecermos/aprendermos quais são os nossos afetos, como afetamos e como somos afetados, ou seja, "trata-se de conhecer/aprender o que nos constitui, o que nos afeta, o que aumenta ou diminui a nossa potência" (DELBONI, 2012, p. 52).

A filosofia de Espinosa postula que o afeto não depende de uma comparação entre ideias. Mesmo que, no sentido clássico, a primazia da ideia sobre o afeto se constitua, as naturezas da ideia e do afeto são diferentes. Para além da comparação intelectual entre ideias, o afeto se constitui na transição ou intensidade de passagem de um grau de perfeição ao outro, na variação... Espinosa (apud DELEUZE, 1978, p. 40) concebe a existência como uma forma de variação contínua:

[...] à medida que uma ideia substitui outra, eu não cesso de passar de um grau de perfeição a outro, mesmo que [a diferença] seja minúscula, e é essa espécie de linha melódica da variação contínua que irá definir o afeto (affectus), ao mesmo tempo, na sua correlação com as ideias e em sua diferença de natureza com as ideias.

Numa crítica a Descartes, que, em suas teorizações, buscava demonstrar a supremacia da mente sobre os afetos, Espinosa, conforme Ramacciotti (2014, p. 63), rompe com a ideia de faculdades autônomas e recusa a separação entre conhecimento e ética, rejeitando, consequentemente, a

[...] noção de liberdade da vontade, Espinosa rejeita todas as teorias dualistas, que estabelecem a hierarquia do princípio inteligível circunscrito à razão enquanto poder absoluto, superior e cindido do princípio sensível circunscrito ao corpo, aos sentidos e aos sentimentos. A teoria da expressividade da substância única e a tese da mesma ordem e da mesma conexão entre as ideias e as coisas estabelecem as bases da filosofia da imanência espinosiana, pois demonstram que os atributos infinitos pensamento e extensão expressam a mesma potência e realidade, por conseguinte, não pode haver hierarquia entre os modos finitos, que os expressam: a mente e o corpo humano.

Ratificando, é a relação nessas linhas de forças que define o grau de potência de elevação ou diminuição do que pode um corpo, do que ele pode sentir e, sobretudo, do que o pensamento pode expressar, pensar. Isso se dá pelo encontro agenciado pelos afetos. "Se, por um lado, toda ideia apreende corpos, quer dizer, todo pensamento possui um corpo, por outro lado, também a todo corpo pertence um campo de ideias" (YONEZAWA; CARDOSO JÚNIOR, 2016, p. 171).

Nas enunciações apresentadas acima, observamos grande ênfase dada aos aspectos do contato, da interação e do encontro, os quais aparecem como dimensões importantes para o êxito das formações.

Nessa dinâmica, a potência de agir é aumentada quando acontece um encontro em que a combinação do corpo que se modifica que age sobre algo ou alguém, está de acordo com a sua própria combinação, com a relação do próprio corpo [Além dos temas serem bastante conectados com a realidade que vivenciamos em nossas unidades de ensino ela nos possibilita o renovo profissional oportunizando o crescimento e aprimoramento profissional]. De modo oposto, se o encontro acontece de forma que a combinação do corpo que o modifica compromete ou destrói uma das combinações, a potência de agir é diminuída ou mesmo encerrada. Nesse fluxo, portanto, evidenciam-se dois afetos/afecções: alegria e tristeza (DELEUZE, 1978).

Nesse fluxo, consideramos a formação continuada docente na modalidade a distância, como um movimento de encontros de corpos coletivos que se agenciam pelo afeto. Os efeitos produzidos por esses encontros, bons encontros, elevaram a potência de agir dos/as professores em formação, sobretudo pela possibilidade de pensar e propor os seus próprios problemas. 


\section{Para não concluir...}

Nessas problematizações, reconhecemos a força do encontro como possibilidade de gerar fluxos, movimentos de aprendizagens, que, nas redes de conversa, se efetivam, sobretudo, quando se consideram as diferentes dimensões que permeiam a formação docente, seja na formação continuada, seja na formação inicial.

As redes de conversações na formação docente são abertura, expansão (CARVALHO, 2006), atuando como um poeta que libera os coletivos moleculares no desejo que eles semeiem o povo por vir; agem, portanto, na contramão do assassino, que elimina o povo existente, com populações moleculares que insistem em tornar a fechar todos os agenciamentos. (DELEUZE; GUATTARI, 1997).

Transpondo para a EAD, quando a formação continuada, na modalidade a distância, se configura apenas com as prescrições limitadas (dia de entrega da tarefa, por quantas linhas ou páginas uma resposta deve se estender, quantas mensagens devem ser postadas no fórum etc.) "assassinam", capturam os movimentos de criação; por outro lado, pensar outros possíveis, como esta experiência vivida pela rede municipal de ensino de Vitória que expande a composição dos cursos com as unidades de ensino, enfatiza o agenciamento da coletividade, fazendo emergir poesia.

No âmbito da experiência dos usos do VixEduca nas unidades de ensino, podemos assistir à evidência da "poesia" em outras situações em que o prescrito não pode acolher: quando na fala da professora 25 que destaca (se referindo ao contexto da Pandemia causa pela COVID 19) "as escolas foram fechadas e os profissionais da educação passaram a desempenhar suas tarefas em homeoffice, a VixEduca estava pronta para nos servir nas formações a distância, não só pela sua estrutura, mas também pelos quase 7.000 usuários inscritos". A professora "25" ainda acrescenta: "Esta proposta começou em 2017, como um projeto piloto e o sucesso foi muito bom e, desde então, a adesão cresce a cada ano e a VixEduca é muito bem avaliada pelos profissionais que a utilizam e atualmente podemos considerá-la como a principal ferramenta de formação da SEME”.

A poesia também é desvelada não apenas na oferta do espaço ou da ferramenta em si, mas sobretudo nos encontros que aproximaram a secretaria de educação com as unidades de ensino e vice-versa ... "as pedagogas/coordenadoras de cada UE participam de uma oficina (em diálogo com a Secretaria de Educação) para implementar a formação, aprendendo a postar os recursos e as atividades oferecidos pela VixEduca" (Professora 25, Técnica da Secretaria).

Também vemos a poesia quando a aposta é compor espaços onde a escola esteja envolvida na criação de movimentos formativos e não apenas executando as ações prescritas. Concordamos com Gallo (2015) em diálogo com Kastrup, reportando-se à obra de Deleuze, Diferença e Repetição, quando aponta a importância da Escola ter espaço, ter direito aos seus próprios problemas e buscar os possíveis na superação ou minimização destes...

\section{Referências}

CARVALHO, J. M. Redes de conversações com um modo singular de realização da formação contínua de professores no cotidiano Escolar. Revista de Ciências Humanas, v. 6, n. 2, p. 281-293, jul./dez. 2006. Disponível em: https://periodicos.ufv.br/RCH/article/view/3572. Acesso em: 14 mar. 2019.

DELBONI, T. M. Z. G. F. Movimentos de corpos de alunos (as) que vibram na criação do conhecimento como o mais potente dos afetos. In: CARVALHO, J. M. (Org.). Infância em territórios curriculares. Petrópolis: DP et Alii, 2012. v. 1, p. 49-61. 
DELEUZE, G. O que é Filosofia? Tradução Bento Prado Jr. E Alberto Alonso Muñoz. 2 ed. Rio de Janeiro. Ed. 34, 1997.

DELEUZE, G. Diferença e repetição. Tradução de Luiz Orlandi e Roberto Machado. 3. ed. São Paulo: Paz e Terra, 2018.

DELEUZE, G. Espinosa e o problema da expressão. 1978. Disponível em: http://conexoesclinicas.com.br/wp-content/uploads/2015/12/DELEUZE-G.-Espinosa-e-oProblema-da-Express\%C3\%A3o1.pdf. Acesso em: 4 mai. 2019.

DELEUZE, G. Aula sobre Spinoza. Disponível em: http://www.webdeleuze.com/php/texte. php,1978. Acesso em: 22 out. 2020.

DIAS, R. de O. Deslocamentos na formação de professores: aprendizagens de adultos e políticas cognitivas. Rio de Janeiro: Lamparina, 2011.

DIAS, R. de O. Formação inventiva como possibilidade de deslocamento. In: DIAS, R. de O. (Org.). Formação inventiva de professores. Rio de Janeiro: Lamparina, 2012.

GALLO, S.; ASPIS, R. (Org.). Deleuze e a Educação. 2015, (46 min 42 seg.). Disponível em: https://www.youtube.com/watch?v=9v6HrC17rVo. Acesso em: 14/02/2021.

YONEZAWA, F.; CARDOSO JÚNIOR, H. R. Deleuze e Spinoza e a vigência do corpoaprendiz: sensibilidade e Educação. In: BRITO, M. dos R. de; GALLO, S. Filosofias da diferença e educação. São Paulo: Livraria da Física, 2016. (Coleção Contextos da Ciência).

KASTRUP, V. A invenção de si e do mundo: uma introdução do tempo e do coletivo no estudo da cognição. Campinas: Papirus, 1999.

RAMACCIOTTI, B. L. Espinosa e Nietzsche: conhecimento como afeto ou paixão mais potente? Cadernos Espinosanos, n. 31, p. 57-80, jul./dez. 2014. Disponível em: http://www.revistas.usp.br/espinosanos/article/view/82438. Acesso em: 18 jul. 2019.

ROLNIK, S. Esferas da insurreição: notas para uma vida não cafetinada. São Paulo: n-1 Edições, 2018.

\section{Sobre as autoras:}

Jaqueline Magalhães Brum. Doutorado em Educação pela Universidade Federal do Espírito Santo, Brasil. Professor Adjunto da Universidade Federal do Espírito Santo, Brasil. E-mail: jackiemagalhaesbrum@gmail.com.

Nilcéa Elias Rodrigues Moreira. Possui graduação em Pedagogia pela Universidade Federal do Espírito Santo, Brasil. Especialização em Educação pela Universidade Federal do Espírito Santo; Especialização em Tecnologias em Educação pela PUC/RJ, parceria SEED/MEC; Mestrado em Educação pela Universidade Federal do Espírito Santo, Doutora em Educação pela Universidade Federal do Espírito Santo - Brasil.

E-mail: doutoradonermoreira@gmail.com. 